\title{
OUTCOME OF HEMISPHERECTOMY FOR REFRACTORY EPILEPSY
}

The clinical features, presurgical workup, and postoperative outcome of 39 patients with medically intractable epilepsy who underwent hemispherectomy from 1996 to 2005 are reported from University of Sao Paulo, Brazil. All patients had preoperative hemiparesis and $76 \%$ were developmentally delayed. Seizures, with onset at 3 years, were tonic in $30 \%$, focal motor in $20 \%$, epilepsia partialis continua (18\%), and complex partial in $10 \%$ of patients. Etiologies included Rasmussen encephalitis (30\%), cortical maldevelopment (23\%), porencephaly $(20 \%)$, gliosis $(15 \%)$, Sturge-Weber syndrome $(5 \%)$, tuberous sclerosis $(2.6 \%)$, and tumors $(2.6 \%)$. Post-surgery at a mean age of 7.5 years (range 2 months to 17 years), $90 \%$ of patients had a $90 \%$ reduction in seizure frequency. An acute worsening of hemiparesis and a hemianopia occurred in all patients, and 3 patients died (1 early with edema and herniation, and 2 late with frequent seizures). A good surgical outcome is expected in patients showing unilateral disease on both video-EEG and MRI. In comparing patients with good or poor outcome, no differences were observed in age of epilepsy, age at surgery, time at seizure recurrence, sex, status epilepticus, side of surgery, surgical technique, and seizure etiology. Patients with bilateral or diffuse EEG findings did not have worse outcomes and did not preclude epilepsy surgery. AED therapy was maintained and in reduced doses for at least 2 years in patients with monotherapy; those on polytherapy had treatment modified to monotherapy when possible. (Terra-Bustamante VC, Inuzuka LM, Fernandes RMF et al. Outcome of hemispheric surgeries for refractory epilepsy in pediatric patients. Childs Nerv Syst March 2007;23:321-326). (Respond: Dr HR Machado, Departmento de Neurologia, Centro de Cirurgia de Epilepsia-CIREP, Campus Universitario, Ribeirao Preto-SP, CEP 14048-900, Sao Paulo, Brazil).

COMMENT. The Johns Hopkins extensive series of hemispherectomies, 111 cases from 1975-2001, demonstrates a beneficial response in $86 \%$ (seizures controlled in $65 \%$ and occasional in $21 \%$ ). The outcome was particularly favorable in children with Rasmussen syndrome and vascular disorders. Seizures due to migrational disorders were less responsive. (Kossof EH. Neurology 2003;61:887-890).

In the Sao Paulo study, seizures were associated with cortical maldevelopment in 10 patients; seizure control was $100 \%$ in 7 and $75 \%$ in 2 . In 12 with Rasmussen syndrome, seizure control was $95-100 \%$ in 11 and $75 \%$ in 1 . Contrary to the Hopkins data, outcome was not significantly correlated with seizure etiology.

\section{$\underline{\text { ANTIEPILEPTIC DRUGS }}$}

\section{LAMOTRIGINE AND SUDDEN UNEXPECTED DEATH IN EPILEPSY}

Four consecutive cases of sudden unexpected death in epilepsy (SUDEP), occurring in non-hospitalized patients while treated with lamotrigine (LTG), between 1995 and 2005, are reported from Stavanger University Hospital, Norway. All were female gender, the epilepsy was idiopathic, age range was 16 to 37 years, and LTG was monotherapy. Seizures 
were generalized tonic clonic, the EEG showed bilateral synchronous epileptiform activity, pulmonary edema was found at autopsy, and a terminal seizure was suspected but not witnessed. Low post-mortem levels of LTG indicated probable non-compliance in 2 patients. Four possible explanations for the SUDEP are proposed: 1) a fatal seizure resulting from LTG non-compliance; 2) LTG-induced ventricular cardiac tachyarrhythmia (torsade de pointes); 3) a combination of LTG effects and seizure; and 4) coincidental unrelated to LTG. (Aurlien D, Tauboll F, Gjerstad L. Lamotrigine in idiopathic epilepsy increased risk of cardiac death? Acta Neurol Scand March 2007;115:199-203). (Respond: Dr Dag Aurlien, Department of Neurology, Stavanger University Hospital, PO Box 8100, 4068 Stavanger, Norway).

COMMENT. LTG is a potential inhibitor of cardiac rapid delayed rectifier potassium ion current, leading to increased risk of arrhythmia and SUDEP (Danielsson BR et al. Epilepsy Res 2005;63:17-25). The above findings might prompt a review of cardiac function by ECG especially in young female patients with idiopathic generalized epilepsy treated with LTG.

\section{VALPROIC ACID-INDUCED HAIR CURLING}

A 47-year-old white female patient treated with valproic acid (VPA) $500 \mathrm{mg} 3 \mathrm{xd}$, at Utrecht University, the Netherlands, developed curling of the hair which gradually resolved over 5 years continuous therapy, with blood levels ranging from 97 to $146 \mathrm{mg} / \mathrm{L}$. Thinning of the hair with spots of alopecia preceded the curling effect and persisted after curling resolved. She had dyed her hair long before the curling appeared, but she had never had a permanent wave hair styling. This report of a transient perming effect of VPA is considered unique. (Wilting I, van Laarhoven JHM, de Koning-Verest IF, Egberts ACG. Valproic acidinduced hair-texture changes in a white woman. Epilepsia Feb 2007;48:400-401). (Reprints: Ms I Wilting, Utrecht University, Faculty of Science, Utrecht Institute for Pharmaceutical Sciences, PO Box 80 082, 3508 TB Utrecht, The Netherlands).

COMMENT. VPA is known to cause alopecia, thinning of the hair, and hair color changes. Changes in hair texture are also reported, including curliness in $2 \%$ of 250 patients (Jeavons PM et al. Lancet 1977;1:359), but rarely transient.

\section{ATTENTION DEFICIT DISORDERS}

\section{LOW BIRTH WEIGHT AND ATTENTION DEFICIT DISORDER}

The relation of low birth weight to the risk of attention deficit hyperactivity disorder was determined in a population-based sample of 1,480 twin pairs ascertained from the Swedish twin registry in the period 1985-1986. Eighteen twin pairs at 8-9 years of age and 10 twin pairs at 13-14 years were discordant for both birth weight and ADHD criteria. The child with ADHD was smaller in 11 of 18 pairs at 8-9 years and in 9 of 10 pairs in adolescence $(\mathrm{P}=0.011)$. The lighter twin had on average $13 \%$ higher ADHD symptom score at age $8-9$ years $(\mathrm{P}=0.006)$ and $12 \%$ higher $\mathrm{ADHD}$ score at age $13-14$ years $(\mathrm{P}=0.018)$ compared with 